\title{
Platelets, lymphocytes and erythrocytes from Alzheimer's disease patients: the quest for blood cell-based biomarkers
}

\author{
Ryszard Pluta ${ }^{1}$, Marzena Ułamek-Kozioł ${ }^{1,2}$, Sławomir Januszewski ${ }^{1}$, Stanisław J. Czuczwar ${ }^{3}$ \\ ${ }^{1}$ Laboratory of Ischemic and Neurodegenerative Brain Research, Mossakowski Medical Research Centre, Polish Academy of Sciences, \\ Warsaw, ${ }^{2}$ First Department of Neurology, Institute of Psychiatry and Neurology, Warsaw, ${ }^{3}$ Department of Pathophysiology, \\ Medical University of Lublin, Lublin, Poland
}

\begin{abstract}
In elderly population, Alzheimer's disease is a common neurodegenerative disorder and accounts for about $70 \%$ of all cases of dementia. The neurodegenerative processes of this disease start presumably 20 years ahead of the clinical beginning of the disorder. The postmortem histopathological examination, brains from Alzheimer's disease patients with characteristic features like amyloid plaques and neurofibrillary tangles, neuronal and synaptic disintegration confirm the final diagnosis of Alzheimer's disease. Senile plaques are composed of $\beta$-amyloid peptide, deriving from the amyloid protein precursor, which is present not only in the brain tissue, but also in other non-neuronal tissues. Some investigations reported that platelets possess amyloid protein precursor and all the enzymatic activities required for the metabolism of this protein throughout the same pathways present in the brain. Thus, platelets may be a good peripheral blood cell-based biomarker to study the onset of Alzheimer's disease. Another line of research indicated molecular and cellular aberrations in blood lymphocytes and erythrocytes from Alzheimer's disease patients and emphasizes the systemic nature of the disease. In this review, we will summarize the recent knowledge on the involvement and/or response of platelets, lymphocytes and red blood cells in the circulation during Alzheimer's disease development. The facts will be reviewed with the special possibility for applying the above blood cells as Alzheimer's disease preclinical and antemortem blood cell-based biomarkers.
\end{abstract}

Key words: Alzheimer's disease, amyloid, diagnostic, blood cell-based biomarkers, platelets, lymphocytes, erythrocytes.

\section{Introduction}

Alzheimer's disease is a devastating neurodegenerative disease characterized by a progressive memory and cognitive decline. It is the most common cause of dementia in the elderly patients, affecting approximately 26 million people worldwide, and whose prevalence has been calculated to quadruple by 2050, thus reaching over $1 \%$ of the total population $[3,5,41]$.
Two forms of Alzheimer's disease have been described: a senile or sporadic form, and a presenile or familial form. The sporadic one develops in $95-98 \%$ of cases, while the familial type is limited to 2-5\% [5]. The neurodegenerative processes of sporadic Alzheimer's disease start presumably 20 years ahead of the clinical beginning of the disorder [42]. The social and economic burden of Alzheimer's disease has been cal-

\section{Communicating author}

Prof. Ryszard Pluta, Laboratory of Ischemic and Neurodegenerative Brain Research, Mossakowski Medical Research Centre,

Polish Academy of Sciences, 5 Pawińskiego St., 02-106 Warsaw, Poland, e-mail: pluta@imdik.pan.pl 
culated - in the USA alone 600 billion dollars per year are spent for Alzheimer's disease patients' care [3]. In the UK, Alzheimer-type dementia costs the economy more than heart and cancer disease together [3].

Nowadays, the diagnosis of an early not preclinical Alzheimer's disease is based on neuropsychological and neuroimaging examination, clinical symptoms of the disease and it is not a definitive diagnosis antemortem [1,24]. At present, final diagnosis of Alzheimer's disease requires presentation of specific postmortem histopathological changes in the brain. The dramatic need for preclinical and correct diagnostic biomarkers of Alzheimer's disease has been raised for several years $[1,24]$. Therefore, the necessity of non-invasive biomarkers that not only help to improve accuracy of diagnosis, but also allow an early/preclinical detection of Alzheimer's disease is evident. An ideal biomarker should identify the molecular processes associated with both neuropathological alternations that characterize the disorder and its correlation with dementia. In Alzheimer's disease, in addition to neuronal changes, a number of peripheral cells are affected including platelets, lymphocytes and erythrocytes. Because these cells are currently no diagnostic markers of Alzheimer's disease, a gradually increasing attention has been given to the need for studying them as blood cell-based biomarkers $[38,45]$. As a way to face this problem, new and non-invasive biomarkers available in blood e.g. platelets, lymphocytes and erythrocytes, are presently under investigation. Platelets have been suggested as a good blood model of the processes occurring in brain in patients with Alzheimer's disease [3,25]. Blood platelets, due to shared biochemical properties with neurons in Alzheimer's disease (increased $\beta$-secretase activity, amyloidogenic processing of amyloid protein precursor) $[3,15]$, can be used as a peripheral model for investigation of neuronal pathology and can constitute an attractive alternative as discussed here [41]. They are the main peripheral source of the amyloid protein precursor, and the analysis of this protein in these cells has been postulated as a biomarker in the diagnosis and follow-up of Alzheimer's disease patients [3]. Another line of research indicated molecular and cellular aberrations in blood lymphocytes and erythrocytes of Alzheimer's disease patients $[20,38,45]$. In any case, the search for simple, reliable, non-invasive, and non-expensive diagnostic tests based on blood cells is an important drive for biomarker research. This review summarizes new data on platelets, lymphocytes and red blood cells as possible biomarkers of Alzheimer's disease. In this review, we present the recent knowledge on the involvement and/or response platelets, lymphocytes and red blood cells during Alzheimer's disease development. The facts will be reviewed with the special possibility for applying the above blood cells as Alzheimer's disease preclinical and antemortem blood cell-based biomarkers. Currently, reliable identification of such molecular characteristics antemortem is problematic due to restricted availability of appropriate sample material and now, the definitive diagnosis is only possible postmortem.

\section{Abnormalities of platelets from Alzheimer's disease patients}

It has been well-known that an amyloid protein precursor was found in platelet alpha granules in high concentrations and is released after platelet degranulation [15]. The whole amyloid protein precursor present in blood serum almost totally comes from platelets. Platelets are also the main source of $\beta$-amyloid peptide in blood plasma ( $90 \%)$, and this secreted peptide is similar to that found in the plaques of Alzheimer's disease subjects ( $\beta$-amyloid peptide 1-42 increased in the extracellular space) [15]. Vessel damage which is observed in Alzheimer's disease is a natural cause of platelet activation and degranulation $[3,20]$. Platelets circulate along the vessel wall responding immediately to vascular injury. The most important of great consequence modifications noted in platelets isolated from Alzheimer's disease patients are: decreased amyloid protein precursor ratio, switch from $\alpha$-secretase to $\beta$-secretase activity that results in amyloidogenic processing of the amyloid protein precursor, and as a consequence, increased platelet activation [3]. This switch from physiological platelets non-amyloidogenic processing to amyloidogenic processing of the amyloid protein precursor is responsible for the increased $\beta$-amyloid peptide generation derived from platelets. In addition, changes in activity of cytochrome $c$ oxidase, monoamine oxidase $\mathrm{B}$, and cyclooxygenase 2 have been observed in platelets from Alzheimer's disease patients [41]. The amyloid protein precursor is present in the cell membrane as an intact protein of about 110 and $130 \mathrm{kDa}$ and as soluble fragments of various lengths in platelet $\alpha$-granules. The mod- 
ified amyloid protein precursor ratio in platelets expresses a positive correlation with the progression of the Alzheimer's disease [3]. This relationship is also present in the preclinical stage of Alzheimer's disease, and probably this can be useful as an early biomarker for Alzheimer's disease diagnosis [3].

Other data showed a significant rise in the number of platelet aggregates, platelet-leukocyte complexes and P-selectin expression in resting platelets from Alzheimer's disease patients [3]. This suggests that platelets from patients with Alzheimer's dis ease exhibit increased basal activation compared to control ones. In one-year follow-up, platelet activation correlates very well with the degree of cognitive decline in Alzheimer's disease subjects [34]. Activated platelets have been shown to adhere to brain vascular amyloid deposits in Alzheimer's disease transgenic mouse model and that causes vessel occlusion $[10,15]$. Platelets deposition in the brain microcirculation may explain the hemostatic abnormalities present in Alzheimer's disease patients [3]. Another essential element of platelet activation is the occurrence of higher levels of coated platelets in Alzheimer's disease subjects. Coated platelets are a subpopulation of activated platelets stimulated by collagen and thrombin and characterized by high procoagulant activity. They expressed a high level of the full-length amyloid protein precursor on cell surface compared to single agonist stimulated cells [31]. A number of coated platelets correlate with Alzheimer's disease progression and they have been shown to intensify inflammation [32]. These data suggest a potential role of coated platelets as a sensitive preclinical biomarker of Alzheimer's disease diagnosis. The presence of tau protein in platelets from Alzheimer's disease patients is suggested as a possible diagnostic biomarker, too [25] It was found that the platelet tau protein displays a significantly higher correlation with Alzheimer's disease than the platelet amyloid protein precursor [8]. Platelets tau protein correlates with regional brain atrophy in patients with Alzheimer's disease [37]. It should be noted here that data on platelet tau protein as Alzheimer's disease biomarker originate from only one research group $[8,25,37]$.

\section{Abnormalities of lymphocytes from Alzheimer's disease patients}

Growing evidence indicates that, in Alzheimer's disease patients, pathological alterations take place not only in the brain tissue, but also in blood cells, such as lymphocytes. Evidently, blood lymphocytes from Alzheimer's disease subjects can be easily available as biomarkers for preclinical and definitive diagnosis and probably drug screening. Impaired $\mathrm{Ca}^{2+}$ homeostasis and endoplasmic reticulum stress are frequently observed both in Alzheimer's disease brain tissue and lymphocytes [21,44]. An increased reactive oxygen species amount, modified activity of antioxidant enzymes, excessive sensitivity of mitochondria, DNA damage and apoptosis were noted in lymphocytes from Alzheimer's disease patients [44]. In this situation, lymphocytes from patients with Alzheimer's disease show the oxidative stress reaction typical for the brain of Alzheimer's disease. Thus, tangible oxidative stress and impairment in the function of mitochondria were noticed in lymphocytes of Alzheimer's disease patients [43]. Above observations suggested the universal nature of oxidative stress in Alzheimer-type dementia and powerfully support the theory that oxidative stress is an early sign in Alzheimer's disease formation. Cell cycle dysregulation is another earlier Alzheimer's disease pathological sign manifested in lymphocytes [16,43]. Additional molecular alterations noted in lymphocytes probably affect their normal immune activity $[2,18]$. Some studies show the decrease in immune activity of lymphocytes due to a low level of blood T as well as B cells $[19,33]$. A number of studies noted the role of T cells in the progress of Alzheimer's disease in connection with the immune system dysfunction, revealed by reduced reactivity of $T$ cells to some pathological factors and a rise of the telomerase level in lymphocytes that leads to reduction of lymphocyte proliferation, the final consequence being the loss of immune system function in Alzheimer's disease subjects $[6,7,9,17,33,36,46]$. That clearly suggests the input of peripheral immune cells to the progress of Alzheimer's disease development.

\section{Abnormalities of erythrocytes from Alzheimer's disease patients}

The available data indicate that erythrocyte $\beta$-amyloid peptide 1-40 and 1-42 may constitute biomarkers for early Alzheimer's disease diagnosis [12]. These data suggest that plasma $\beta$-amyloid peptides bind to erythrocytes possibly with aging, implying a pathogenic role of erythrocyte amyloid complex. $\beta$-amyloid peptides $1-40$ and 1-42 were noted also 
inside erythrocytes where their levels were established to be 8- and 14-times higher than in serum, respectively [12]. Erythrocyte amyloid complex induces the red blood cell changes in morphology, adhesion to endothelium and influences vessel activity $[22,38]$. Current results indicate that $98 \%$ of erythrocytes from Alzheimer's disease patients are amyloid binding-positive but only $38 \%$ of such red cell-binding is noted in healthy subjects [45]. The ischemic hypothesis of Alzheimer's disease etiology holds the view that abnormalities in blood supply to brain seem a primary trigger for neurodegeneration with Alzheimer-genotype and phenotype [13,26-30,39,40]. Moreover, the results indicate that erythrocyte $\beta$-amyloid peptide 1-40 and 1-42 may create blood cellsbased biomarkers of Alzheimer's disease diagnosis. Amyloid binding causes oxidative stress and reactive oxygen species generation in erythrocytes and induces accumulation of phospholipid hydroperoxides, a characteristic indicator for erythrocyte damage [23]. It was noted that erythrocyte protein kinase C could play a primary role in amyloid-induced oxidative stress unbalance and develop conformational changes of erythrocyte external acetylcholinesterase located on their external side [4]. Furthermore, since mechanical properties of erythrocytes membrane are regulated by a number of molecular components of signaling and regulatory pathways, of these, particular interest has been addressed toward nitric oxide metabolism, due to its dependence on acetylcholinesterase. Likewise, in red blood cells from Alzheimer's disease patients increased oxidative stress is revealed in the raised levels of hydrogen peroxide and decreased glutathione/glutathione disulfide ratio and glutathione transferase activity [14]. Also red blood cells from Alzheimer's disease subjects disclosed increased activity of hexokinase, phosphofructokinase, bisphosphoglycerate mutase and bisphosphoglycerate phosphatase [45]. Additionally, low levels of long-chain polyunsaturated fatty acids have been shown in erythrocyte membranes compared with healthy subjects [35]. Finally, erythrocyte membrane proteins such as the glucose transporter, calpain-1, band 3 protein, Hsp 90 and IgG were changed in patients with Alzheimer's disease [38]. Above presented changes in red blood cells from Alzheimer's disease patients support the ischemic hypothesis of Alzheimer's disease and contribute to the molecular reflection of Alzheimer's disease in red blood cells $[13,26-30,39,40]$.

\section{Conclusions}

Despite several promising advances in Alzheimer's disease biomarkers [1], effective predictive biomarkers of this disease are still elusive and now diagnosis relies on cognitive symptoms characteristic of the advanced stage of the disorder. This review summaries platelets, lymphocytes and erythrocytes as Alzheimer's disease potential blood cell-based biomarkers, their role, implication and alteration in the disease. This review also suggests that platelets, lymphocytes and erythrocytes appear just as relevant in this area of biomarker research.

Alzheimer's disease in the beginning was identified as only brain parenchyma disease, over the last decades being again evaluated as a disorder relating with various other peripheral tissue and cell pathologies in the organism $[3,25,26,38,41,45]$. Indeed, it has been actually very well established that molecular changes in Alzheimer's disease patients do not occur only in the brain tissue, but even in blood cells and blood vessels $[3,25,38,41,45]$. Blood platelets, due to shared biochemical properties with neurons, can be used as a model for studying neuronal pathology [41]. Scientists have recognized that platelets, as circulatory blood elements, are affected not only in the onset but even in the progression of Alzheimer's disease. Platelets mirror what happens in brain tissue during the progress of Alzheimer's disease, and represent the cell type in which the early molecular processes in the onset of the disease can be identified. Unlike neurons, platelets can be without trouble accessible and make a valid cellular tool to investigate the neuropathogenesis of Alzheimer's disease.

Growing evidence brings out neuroinflammation as a very important process in Alzheimer's disease neuropathogenesis in the early and late disease stages [11]. Amongst mediators which considerably play a role in Alzheimer's disease neuroinflammatory processes are lymphocytes which migrate from blood through the blood-brain barrier to the Alzheimer's disease brain [20]. The neuroinflammatory factors present in the blood, as well as cellular and molecular changes in lymphocytes from Alzheimer's disease patients, are a promise for blood cell-based biomarkers for diagnosis of the early and progressing late stages of the disease. On the other hand, little is known on characteristic immune factors for Alzheimer's disease stages, due to imprecise recruit- 
ment of patients for such investigations. Further blood cell-based biomarker progress requires development of characteristic immune mediators for the preclinical, moderate and late antemortem diagnosis of Alzheimer's disease stages. Molecular modifications in lymphocytes in the early Alzheimer's disease cases provide a view into the processes of disease progress and promise biochemical biomarkers for early disorder identification, in addition to monitoring its responses to therapeutics. This concept may transform diagnostics, shifting its focus from clinical symptoms to molecular processes.

In this review, we present a number of potentially useful red blood cell biomarkers for Alzheimer's disease cases. These include red blood cell morphology, their membrane proteins as the glucose transporter, $\beta$-amyloid peptide, IgG, Hsp 90, band 3 protein, calpain-1 and oxidative stress. Of these molecules identified, $\beta$-amyloid peptide, Hsp 90, band 3 protein and calpain-1 indicate the most promising features as preclinical biomarkers. Nonetheless, the most exciting aspect of red blood cells is their changed morphology in Alzheimer-type dementia [38]. The changed morphology not only could be used as a diagnostic test but may be essential in early neuropathogenesis of the disorder.

In this review, we have summarized the limited and often discordant recent findings of potential preclinical Alzheimer's disease molecular diagnostic blood cell-based biomarkers in platelets, lymphocytes and red blood cells. Both in vitro and in vivo studies are aimed to understand in which way inflammatory processes, affected proteins, enzymes, signal transduction pathways and spontaneous activation are important in platelets, lymphocytes and erythrocytes to better define the molecular processes in Alzheimer's disease cases. Platelets are the principal players in organism homeostasis, but they also play a key role in Alzheimer's disease pathogenesis still remaining a potential biomarker to disease diagnosis.

Further studies must be done to set up the causal linkage between the circulatory blood elements in Alzheimer's disease brain. In light of the heterogeneity and complexity of Alzheimer's disease cases, the future blood molecular processes of disease will most likely be developed based on an integrated panel of various molecules in blood cells, in addition to blood serum, including proteins, DNA and miRNA changes and/or lipids. Further investigations will be needed to validate these blood cell-based biomark- ers which could be used alone, combined, and/or in association with the classic biomarkers. Such a combined approach will make a precise determination of Alzheimer's disease stages and personal therapy. In addition, the correlation between blood biochemical biomarkers, brain imaging, clinical symptoms and neuropsychological tests seems necessary for further progress in solving the disorder etiology and mechanisms, in addition to diagnostics and therapy. This added new interesting evidence which directs to peripheral blood cells as a possible source for new and quick antemortem diagnostic blood cell-based biomarkers, in view of the fact that numerous modifications can be found in these cells in Alzheimer's disease cases.

\section{Acknowledgements}

The authors acknowledge the support provided by the Mossakowski Medical Research Centre, Polish Academy of Sciences, Poland (T3-RP), and by the statutory grants from the Medical University of Lublin, Poland (SJC).

\section{Disclosure}

The authors report no conflict of interest.

\section{References}

1. Blennow K, Dubois B, Fagan AM, Lewczuk P, de Leone MJ, Hampel $\mathrm{H}$. Clinical utility of cerebrospinal fluid biomarkers in the diagnosis of early Alzheimer's disease. Alzheimers Dement 2015; 11: 58-69.

2. Bulati M, Buffa S, Martorana A, Gervasi F, Camarda C, Azzarello DM, Monastero R, Caruso C, Colonna-Romano G. Double negative (IgG+lgDCD27-) B cells are increased in a cohort of moderate-severe Alzheimer's disease patients and show a proinflammatory trafficking receptor phenotype. J Alzheimer's Dis 2015; 44: 1241-1251.

3. Canobbio I, Abubaker AA, Visconte C, Torti M, Pula G. Role of amyloid peptides in vascular dysfunction and platelet dysregulation in Alzheimer's disease. Front Cell Neurosci 2015; 9: 65.

4. Carelli-Alinovi C, Ficarra S, Russo AM, Giunta E, Barreca D, Galtieri A, Misiti F, Tellone E. Involvement of acetylcholinesterase and protein kinase $C$ in the protective effect of caffeine against $\beta$-amyloid-induced alterations in red blood cells. Biochimie 2016; 121: 52-59.

5. Catricala S, Torti M, Ricevuti G. Alzheimer disease and platelets: how's that relevant. Immun Ageing 2012; 9: 20.

6. Da Mesquita SA, Ferreira C, Sousa JC, Correia-Neves M, Sousa N, Marques F. Insights on the pathophysiology of Alzheimer's disease: the crosstalk between amyloid pathology, neuroinflammation and the peripheral immune system. Neurosci Biobehav Rev 2016; 68: 547-562. 
7. Deardorff WJ, Grossberg GT. Targeting neuroinflammation in Alzheimer's disease: evidence for NSAIDs and novel therapeutics. Expert Rev Neurother 2017; 17: 17-32.

8. Farıas G, Perez P, Slachevsky A, Maccioni RB. Platelet tau pattern correlates with cognitive status in Alzheimer's disease. J Alzheimer's Dis 2012; 31: 65-69.

9. Giubilei F, Antonini G, Montesperelli C, Sepe-Monti M, Cannoni S, Pichi A, Tisei P, Casini AR, Buttinelli C, Prencipe M, Salvetti M, Ristori G. T cell response to amyloid- $\beta$ and to mitochondrial antigens in Alzheimer's disease. Dement Geriatr Cogn Disord 2003; 16: 35-38.

10. Gowert NS, Donner L, Chatterjee M, Eisele YS, Towhid ST, Münzer P, Walker B, Ogorek I, Borst O, Grandoch M, Schaller M, Fischer JW, Gawaz M, Weggen S, Lang F, Jucker M, Elvers M. Blood platelets in the progression of Alzheimer's disease. PLoS One 2014; 9: e90523.

11. Heneka TM, Carson MJ, Khoury JE, Landreth GE, Brosseron F, Feinstein DL, Jacobs AH, Wyss-Coray T, Vitorica J, Ransohoff RM, Herrup K, Frautschy SA, Finsen B, Brown GC, Verkhratsky A, Yamanaka K, Koistinaho J, Latz E, Halle A, Petzold GC, Town T, Morgan D, Shinohara ML, Perry VH, Holmes C, Bazan NG, Brooks DJ, Hunot S, Joseph B, Deigendesch N, Garaschuk O, Boddeke E, Dinarello CA, Breitner JC, Cole GM, Golenbock DT, Kummer MP. Neuroinflammation in Alzheimer's disease. Lancet Neurol 2015; 14: 388-405.

12. Kiko T, Nakagawa K, Satoh A, Tsuduki T, Furukawa K, Arai H, Miyazawa T. Amyloid beta levels in human red blood cells. PLoS One 2012; 7: e49620.

13. Kocki J, Ułamek-Kozioł M, Bogucka-Kocka A, Januszewski S, Jabłoński M, Gil-Kulik P, Brzozowska J, Petniak A, FurmagaJabłońska W, Bogucki J, Czuczwar SJ, Pluta R. Dysregulation of amyloid- $\beta$ protein precursor, $\beta$-secretase, presenilin 1 and 2 genes in the rat selectively vulnerable CA1 subfield of hippocampus following transient global brain ischemia. J Alzheimer's Dis 2015; 47: 1047-1056.

14. Kosenko EA, Aliev G, Kaminsky YG. Relationship between chronic disturbance of 2,3-diphosphoglycerate metabolism in erythrocytes and Alzheimer disease. CNS Neurol Disord Drug Targets 2016; 15: 113-123.

15. Kucheryavykh LY, Dávila-Rodríguez J, Rivera-Aponte DE, Zueva LV, Washington AV, Sanabria P, Inyushin MY. Platelets are responsible for the accumulation of beta-amyloid in blood clots inside and around blood vessels in mouse brain after thrombosis. Brain Res Bull 2017; 128: 98-105.

16. Kuhla A, Ludwig SC, Kuhla B, Münch G, Vollmar B. Advanced glycation end products are mitogenic signals and trigger cell cycle reentry of neurons in Alzheimer's disease brain. Neurobiol Aging 2015; 36: 753-761.

17. Licastro F, Porcellini E. Persistent infections, immune-senescence and Alzheimer's disease. Oncoscience 2016; 3: 135-142.

18. Lueg G, Gross CC, Lohmann H, Johnen A, Kemmling A, Deppe M, Groger J, Minnerup J, Wiendl H, Meuth SG, Duning T. Clinical relevance of specific T-cell activation in the blood and cerebrospinal fluid of patients with mild Alzheimer's disease. Neurobiol Aging 2015; 36: 81-89.
19. Martorana A, Bulati M, Buffa S, Pellicanò M, Caruso C, Candore G, Colonna-Romano G. Immunosenescence, inflammation and Alzheimer's disease. Longev Healthspan 2012; 1: 8.

20. Mietelska-Porowska A, Wojda U. T lymphocytes and inflammatory mediators in the interplay between brain and blood in Alzheimer's disease: Potential pools of new biomarkers. I Immunol Res 2017; 2017: 17.

21. Mota SI, Costa RO, Ferreira IL, Santana I, Caldeira GL, Padovano C, Fonseca AC, Baldeiras I, Cunha C, Letra L, Oliveira CR, Pereira CM, Rego AC. Oxidative stress involving changes in Nrf2 and ER stress in early stages of Alzheimer's disease. Biochim Biophys Acta 2015; 1852: 1428-1441.

22. Nakagawa K, Kiko T, Kuriwada S, Miyazawa T, Kimura F, Miyazawa T. Amyloid $\beta$ induces adhesion of erythrocytes to endothelial cells and affects endothelial viability and functionality. Biosci Biotechnol Biochem 2011; 75: 2030-2033.

23. Nakagawa K, Kiko T, Miyazawa T, Sookwong P, Tsuduki T, Satoh A, Miyazawa T. Amyloid $\beta$-induced erythrocytic damage and its attenuation by carotenoids. FEBS Lett 2011; 585: 1249-1254.

24. Nesteruk M, Nesteruk T, Styczyńska M,Mandecka M, Barczak A, Barcikowska M. Combined use of biochemical and volumetric biomarkers to assess the risk of conversion of mild cognitive impairment to Alzheimer's disease. Folia Neuropathol 2016; 54 : 369-374.

25. Neumann K, Farias G, Slachevsky A, Perez P, Maccioni RB. Human platelet tau: A potential peripheral marker for Alzheimer's disease. J Alzheimer's Dis 2011; 25: 103-109.

26. Pluta R, Ułamek M, Jabłoński M. Alzheimer's mechanisms in ischemic brain degeneration. Anat Rec 2009; 292: 1863-1881.

27. Pluta R, Furmaga-Jabłońska W, Maciejewski R, Ułamek-Kozioł M, Jabłoński M. Brain ischemia activates beta- and gamma-secretase cleavage of amyloid precursor protein: significance in sporadic Alzheimer's disease. Mol Neurobiol 2013; 47: 425-434.

28. Pluta R, Jabłoński M, Ułamek-Kozioł M, Kocki J, Brzozowska J, Januszewski S, Furmaga-Jabłońska W, Bogucka-Kocka A, Maciejewski R, Czuczwar SJ. Sporadic Alzheimer'sdisease begins as episodes of brain ischemia and ischemically dysregulated Alzheimer's disease genes. Mol Neurobiol 2013; 48: 500-515.

29. Pluta R, Kocki J, Ułamek-Kozioł M, Petniak A, Gil-Kulik P, Januszewski S, Bogucki J, Jabłoński M, Brzozowska J, Furmaga-Jabłońska W, Bogucka-Kocka A, Czuczwar SJ. Discrepancy in expression of $\beta$-secretase and amyloid- $\beta$ protein precursor in Alzheimer-related genes in the rat medial temporal lobe cortex following transient global brain ischemia. J Alzheimers Dis 2016; 51: 1023-1031.

30. Pluta R, Kocki J, Ułamek-Kozioł M, Bogucka-Kocka A, Gil-Kulik P, Januszewski S Jabłoński M, Petniak A, Brzozowska J, Bogucki J, Furmaga-Jabłońska W, Czuczwar SJ. Alzheimer-associated presenilin 2 gene is dysregulated in rat medial temporal lobe cortex after complete brain ischemia due to cardiac arrest. Pharmacol Rep 2016; 68: 155-161.

31. Prodan Cl, Szasz R, Vincent AS, Ross ED, Dale GL. Coated platelets retain amyloid precursor protein on their surface. Platelets 2006; 17: 56-60

32. Prodan $\mathrm{Cl}$, Ross ED, Vincent AS, Dale GL. Rate of progression in Alzheimer's disease correlates with coated-platelet levels a longitudinal study. Transl Res 2008; 152: 99-102. 
33. Richartz-Salzburger E, Batra A, Stransky E, Laske C, Köhler N, Bartels M, Buchkremer G, Schott K. Altered lymphocyte distribution in Alzheimer's disease. J Psychiatr Res 2007; 41: 174-178.

34. Sakurai H, Hanyu H, Sato T, Kume K, Hirao K, Kanetaka H, Iwamoto T. Effects of cilostazol on cognition and regional cerebra blood flow in patients with Alzheimer's disease and cerebrovascular disease: a pilot study. Geriatr Gerontol Int 2013; 13: 90-97.

35. Schuchardt JP, Köbe T, Witte V, Willers J, Gingrich A, Tesky V, Pantel J, Rujescu D, Illig T, Flöel A, Hahn A. Genetic variants of the FADS gene cluster are associated with erythrocyte membrane LC PUFA levels in patients with mild cognitive impairment. J Nutr Health Aging 2016; 20: 611-620.

36. Schwartz M, Deczkowska A. Neurological disease as a failure of brain-immune crosstalk: the multiple faces of neuroinflammation. Trends Immunol 2016; 37: 668-679.

37. Slachevsky A, Guzman-Martınez L, Delgado C, Reyes P, Farıas GA, Munoz-Neira C, Bravo E, Farıas M, Flores P, Garrido C, Becker JT, Lopez OL, Maccioni RB. Tau platelets correlate with regional brain atrophy in patients with Alzheimer's disease. J Alzheimer's Dis 2017; 55: 1595-1603.

38. Stevenson A, Lopez D, Khoo P, Kalaria RN, Mukaetova-Ladinska EB. Exploring erythrocytes as blood biomarkers for Alzheimer's disease. J Alzheimers Dis 2017; 60: 845-857.

39. Ułamek-Kozioł M, Kocki J, Bogucka-Kocka A, Petniak A, Gil-Kulik P, Januszewski S, Bogucki J, Jabłoński M, Furmaga-Jabłońska W, Brzozowska J, Czuczwar SJ, Pluta R. Dysregulation of autophagy, mitophagy and apoptotic genes in the medial temporal lobe cortex in an ischemic model of Alzheimer's disease. J Alzheimers Dis 2016; 54: 113-121.

40. Ułamek-Kozioł M, Kocki J, Bogucka-Kocka A, Januszewski S, Bogucki J, Czuczwar SJ, Pluta R. Autophagy, mitophagy and apoptotic gene changes in the hippocampal CA1 area in a rat ischemic model of Alzheimer's disease. Pharmacol Rep 2017; 69: 1289-1294.

41. Veitinger M, Varga B, Guterres SB, Zellner M. Platelets, a reliable source for peripheral Alzheimer's disease biomarkers? Acta Neuropathol Commun 2014; 2: 65.

42. Villemagne VL, Burnham S, Bourgeat P, Brown B, Ellis KA, Salvado O, Szoeke C, Macaulay SL, Martins R, Maruff P, Ames D, Rowe CC, Masters CL. Amyloid beta deposition, neurodegeneration, and cognitive decline in sporadic Alzheimer's disease: A prospective cohort study. Lancet Neurol 2013; 12: 357-367.

43. Wojda U. Alzheimer's disease lymphocytes: potential for biomarkers? Biomark Med 2016; 10: 1-4.

44. Wojsiat J, Prandelli C, Laskowska-Kaszub K, Martín Requero A Wojda U. Oxidative stress and aberrant cell cycle in Alzheimer's disease lymphocytes: diagnostic prospects. J Alzheimer's Dis 2015; 46: 329-350.

45. Wojsiat J, Laskowska-Kaszub K, Mietelska-Porowska A, Wojda U. Search for Alzheimer's disease biomarkers in blood cells: hypotheses-driven approach. Biomark Med 2017; 11: 917-931.

46. Zhang J, Kong Q, Zhang Z, Ge P, Ba D, He W. Telomere dysfunction of lymphocytes in patients with Alzheimer disease. Cogn Behav Neurol 2003; 16: 170-176. 